\title{
Adnexal carcinomas of the head and neck
}

\author{
Jorge O. Güerrissi, Juan Pablo Quiroga
}

Argerich Hospital, Buenos Aires, Argentina.

Address for Corrsepondence: Dr. Jorge O. Güerrissi, Libertad 985, Quilmes (1878), Argentina. E-mail: guerrisi@speedy.com.ar

\section{ABSTRACT}

Adnexal carcinomas of the skin are rare and they derive from structures such as sweat glands, sebaceous glands, and hair follicles. Adnexal tumors represent $1-2 \%$ of skin cancers. Between 1998 and 2004, eight patients with malignant adnexal tumors of the head and neck were treated in the Plastic Surgery Service in Argerich Hospital in Buenos Aires, Argentina. Four (50\%) of them had malignant cylindromas, two $(25 \%)$ had sebaceous carcinoma, and the other two (25\%) syringoid eccrine carcinoma. Tumor resection and local flaps were made in all cases. In one case, a radical neck dissection with superficial parotidectomy was performed to treat the metastatic cervical nodes. Local recurrence observed in two cases $(25 \%)$ was associated with distant metastasis and death of the patients. In other six cases, the survival rate was $75 \%$ after five years.

\section{KEY WORDS}

Adnexal carcinomas, adnexal tumors, skin cancer

\section{INTRODUCTION}

elanoma skin cancers account for $4-7 \%$ of all skin cancers, the non melanoma tumours for 93-96\% Both basal cell and squamous cell carcinomas represent $>80 \%$ of non melanoma skin cancers whereas benign and malign adnexal tumours represent only $1-2 \%$ including mesenchymal, fatty, and vascular tumours. Adnexal carcinomas of the skin derive from structures that have a common origin such as the apocrine and eccrine sweat glands, sebaceous glands, and hair follicles [Table 1]. Malignant adnexal tumours are frequently located in the head and neck region but may appear on the fingers and toes, the trunk as well as the extremities. ${ }^{[1-4]}$

All ages may be affected and there is no easily identifiable risk group.
Most adnexal carcinomas of the skin are highly malignant and difficult to diagnose clinically or even histologically.

The objective of this presentation is to attract the attention of plastic surgeons because a reliable cure rate is associated with prompt recognition and aggressive treatment.

\section{MATERIAL AND METHODS}

Between 1998 and 2004, eight patients with adnexal carcinomas of the skin in the head and neck region were admitted to the Service of Plastic Surgery in the Argerich Hospital. Four $(50 \%$ of them were diagnosed with malignant cylindromas; two $(25 \%)$ with sebaceous carcinoma, and the remaining two $(25 \%)$ with syringoid eccrine carcinoma. The patients' ages ranged from 26 to 68 years and the follow-up period was for five years. 
Table 1: Adnexal carcinomas of the skin ADNEXAL CARCINOMAS

\begin{tabular}{lll}
\hline Sebaceous tumors & Hair follicle tumors & Sweat gland tumors \\
\hline 1. Sebaceous & 1. Merkel Cell Carcinoma & Low grade \\
Carcinoma & 2. Pilomatrixoma and pilomatrix & 1. Eccrine epithelioma \\
& Carcinoma & 2. Adenoidocystic Carcinoma \\
& 3. Mucinous Carcinoma \\
& 4. Extramammary Paget \\
& Intermediate grade \\
& 1. Porocarcinoma \\
& 2. Digital Papillary Adenocarcinoma \\
& High grade \\
& 1. Apocrine Adenocarcinoma \\
& 2. Eccrine duct Carcinoma \\
& 3. Spiroadenocarcinoma \\
4. Malignant Cylindroma
\end{tabular}

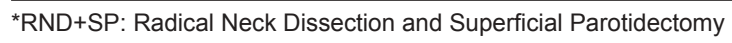

Table 2: Surgical treatment and Follow-up

\begin{tabular}{|c|c|c|c|c|c|c|}
\hline Case & Age/Sex & Site & Histology & Treatment & Recurrence & Survival \\
\hline 1 & $52 / \mathrm{M}$ & Scalp & Malignant Cylindroma & Resection + Flap & Yes +Metastasis & 1 year \\
\hline 2 & $34 / F$ & Cheek & Malignant Cylindroma & Resection + Flap & No & 5 years \\
\hline 3 & $26 / F$ & Scalp & Malignant Cylindroma & Resection + Flap & No & 5 years \\
\hline 4 & $57 / \mathrm{M}$ & Scalp & Malignant Cylindroma & Resection + Flap & No & 5 years \\
\hline 5 & $68 / F$ & Upper Lid & Sebaceous Cylindroma & $\begin{array}{c}\text { Resection + Flap } \\
\text { RND+SP * }\end{array}$ & No & 5 years \\
\hline 6 & $49 / F$ & Cheek & Sebaceous Carcinoma & Resection + Flap & No & 5 years \\
\hline 7 & $47 / F$ & Scalp & Syringoma & Resection + Flap & Yes + Metastasis & 3 years \\
\hline 8 & $50 / \mathrm{M}$ & Nose & Syringoma & Resection + Skin graft & No & 5 years \\
\hline
\end{tabular}

Local recurrence was observed in two cases (25\%) with malignant cylindroma and syringomoid eccrine carcinoma.

The treatment of choice was a wide excision of the tumour $(>1.5 \mathrm{~cm})$ and local flaps for reconstruction in seven cases and a split-thickness skin graft in the other case.

A radical neck dissection including superficial parotidectomy was done in one of the two cases of sebaceous carcinoma when metastatic cervical nodes were detected.

Six patients (75\%) were followed up for at least five years; two others (25\%) died of local recurrence and distant metastasis within a mean follow-up period of 36 months [Table 2].

In these two patients, chemotherapy and radiotherapy were used with very limited success.

Major complications were not observed and only two cases presented with infection of the incision.

\section{Malignant cylindroma}

Case 1: A 52 year-old man presented a recurrent malignant cylindroma on his scalp [Figure 1] Excision of the tumour and a pedicled scalp flap based on the superficial temporal artery was performed [Figures 2-3]. Histological findings showed multiple compact epithelial lobes with central cells with wide nuclei and peripheral cells with small and dark nuclei. Approximately after two years, the patient presented the first recurrence at the level of the upper insertion of the trapezius muscle and a new surgical excision was carried out. After five months, a new and very aggressive recurrence was exhibited that involved the brain and the meninges as well as distant metastasis [Figure 4]. Adjuvant radiotherapy was unsuccessfully applied on the local recurrent lesion but he died nine months after the last surgery.

\section{Sebaceous carcinoma}

Case 2: A 68 year-old woman presented with a tumour at the border of the right superior eyelid. Biopsy 


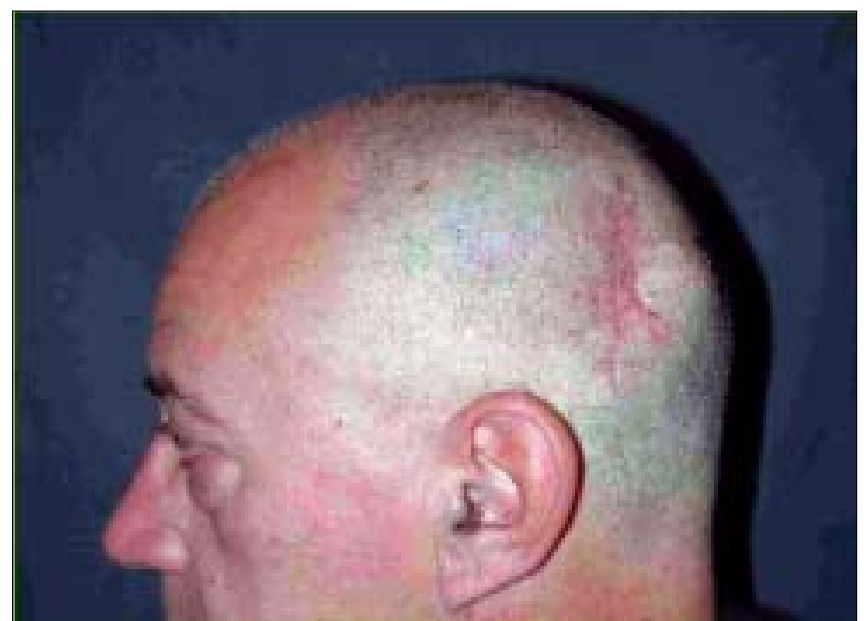

Figure 1: Cylindroma of the scalp

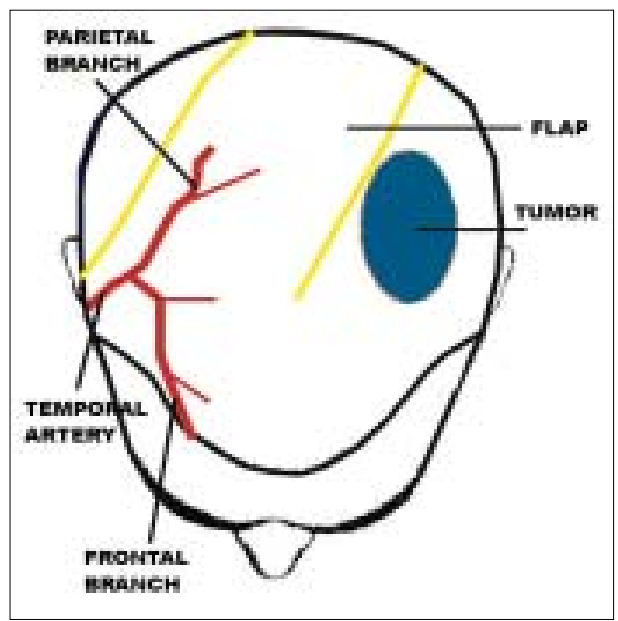

Figure 3: Schematic drawing of the scalp flap

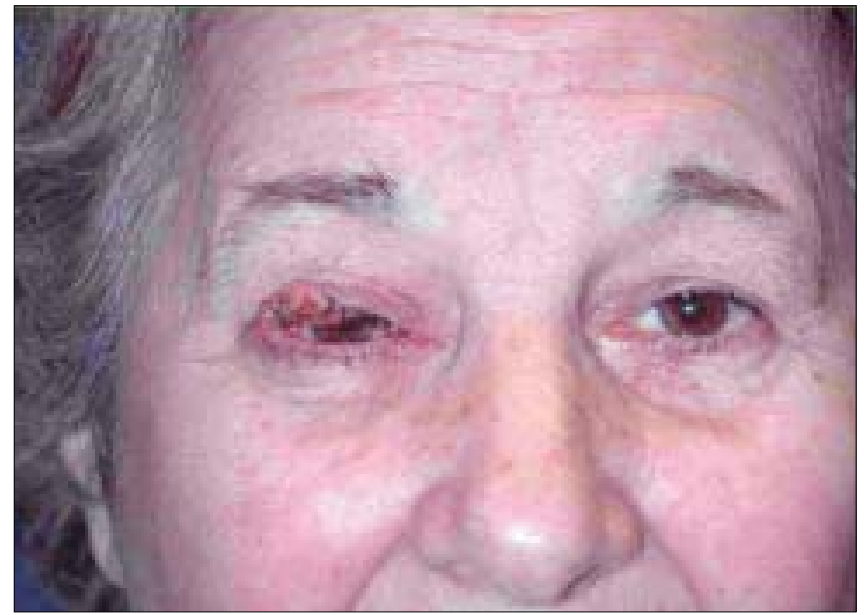

Figure 5: Sebaceous carcinoma on the superior right eyelid superior

results indicated a carcinoma of the sebaceous cells [Figure 5]. Complete tumor resection was carried out and eyelid reconstruction was performed with graft of

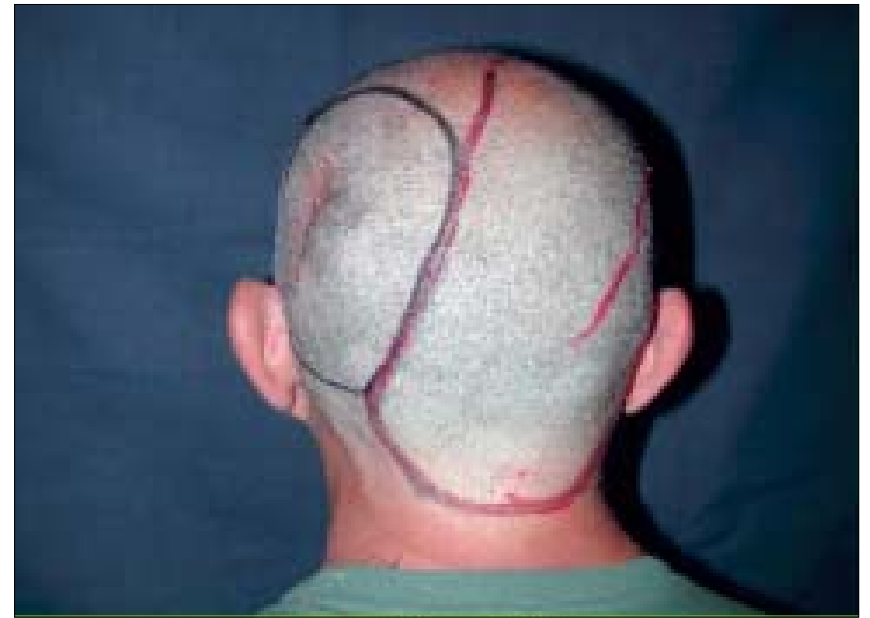

Figure 2: Area of resection and drawing flaps of the scalp

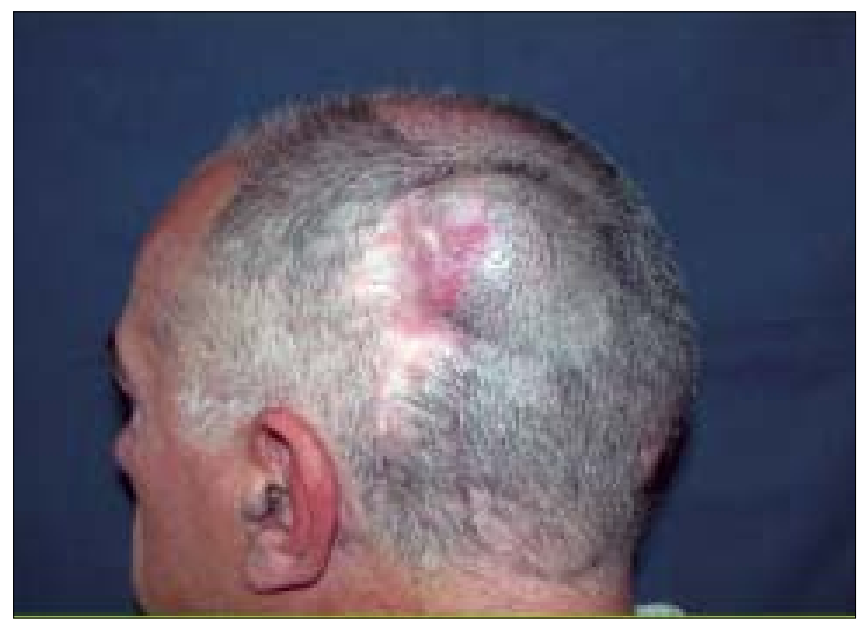

Figure 4: Aggressive local recurrence

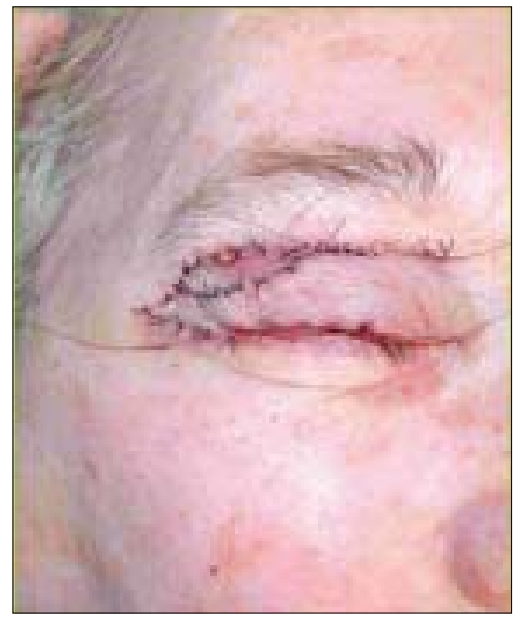

Figure 6: Eyelid reconstruction by means of an orbicularioculis musculocutaneous flap

the palate mucosa and an ipsilateral orbicularis oculi musculocutaneous flap [Figure 6]. Metastatic cervical nodes were detected after two months, and a radical Indian J Plast Surg July-December 2008 Vol 41 Issue 2 
neck dissection was done with superficial parotidectomy. Excellent aesthetic and functional results were obtained after five years [Figure 7].

\section{Syringoid eccrine carcinoma}

Case 3: A 47 year-old woman presented with a tumour of the scalp. Biopsy results indicated a syringoid eccrine carcinoma [Figure 8]. A wide tumour excision was planned [Figure 9] and a scalp flap was designed to cover the defect based on the superficial temporary artery [Figure 10]. Excellent aesthetic and functional results were obtained and recurrence was not detected after five years [Figure 11].

\section{DISCUSSION}

The adnexal carcinomas of the skin are not frequent and they derive from the foetal epidermis. ${ }^{[16]}$ Some

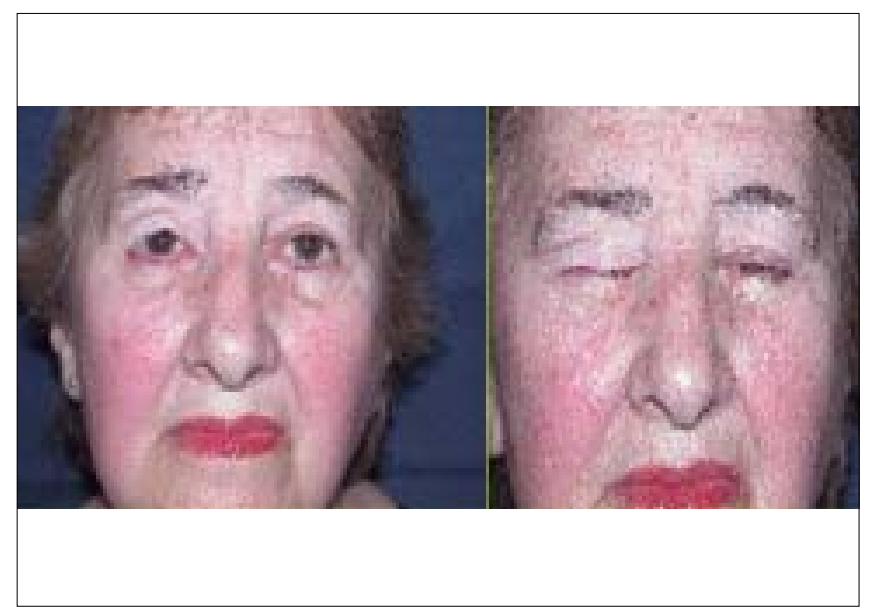

Figure 7: Postsurgical result

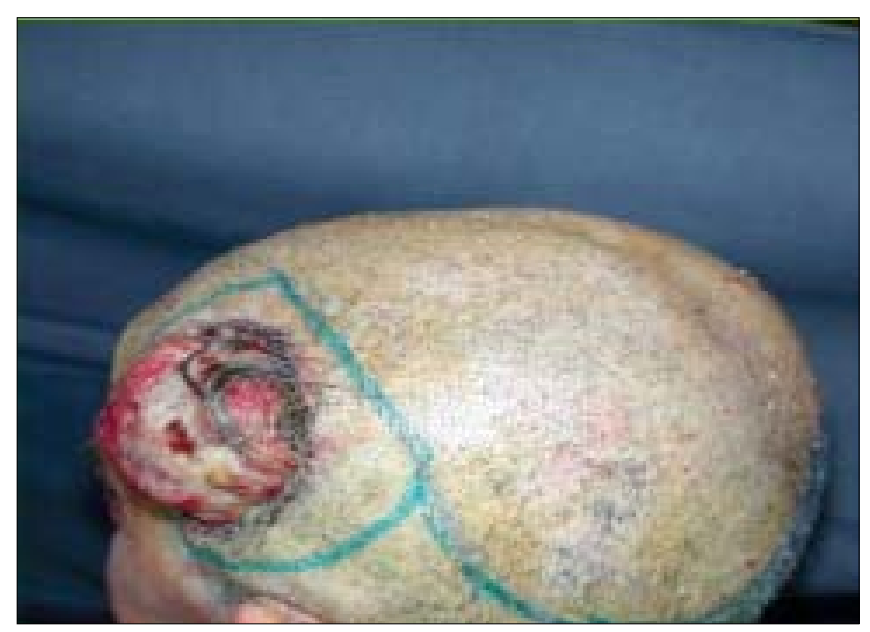

Figure 9: Resection of the tumor and a designed scalp flap have a predilection for certain specific locations such as syringomas of the cheek and nose; cylindromas of the scalp and face; sebaceous carcinoma in the eyelids, etc.

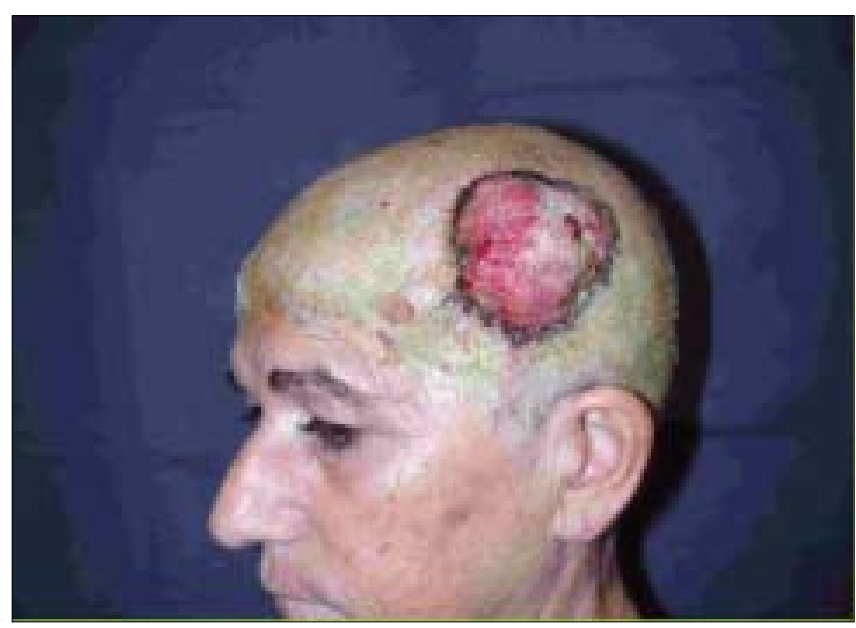

Figure 8: Syringoid eccrine carcinoma of the scalp

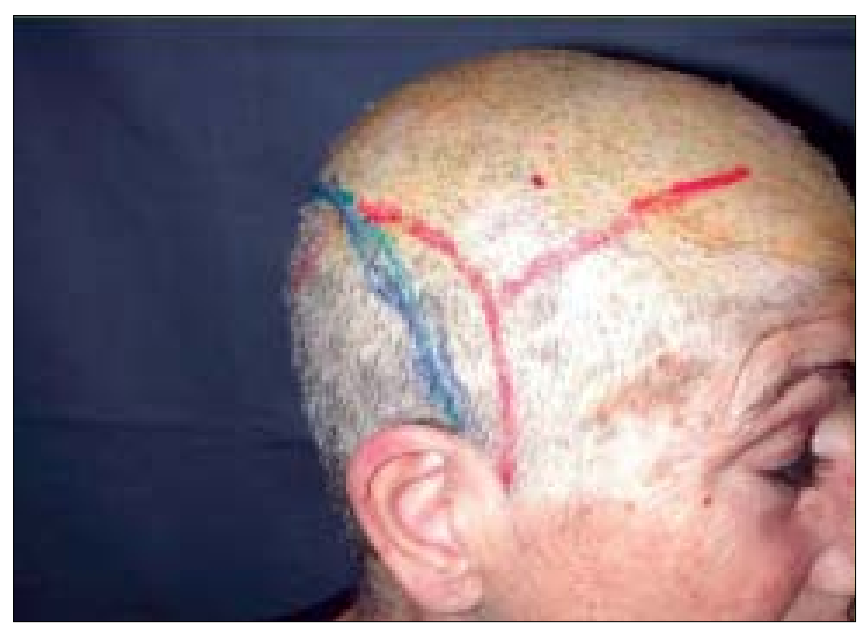

Figure 10: Irrigation of the scalp flap

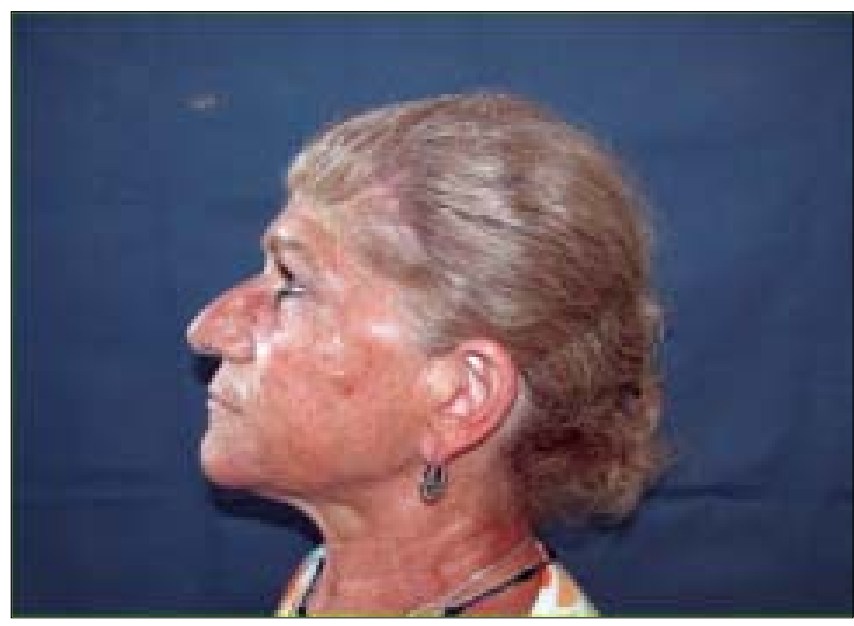

Figure 11: Postsurgical result after two years 
Clinical diagnosis of most adnexal skin carcinomas is difficult not only between them but also with adnexal benign tumours.

Factors suggesting malignancy include poor demarcation, tumour necrosis, ulcers, border, tumour infiltration, etc.

Malignant cylindroma is a rare tumour derived from the eccrine sweat glands. ${ }^{[5]}$ Its origin was formerly considered to be the apocrine sweat gland but is now thought to be due to a mixed aetiology. Only 14 cases are known in literature and they have all presented with aggressive local expansion, perforation of the skull, and metastasis in the cervical nodes. ${ }^{[6-8,10-12]}$ They appear frequently in women and young adults as nodules $1.2-6 \mathrm{~cm}$ in diameter; pink in colour and of firm consistency. They may appear in two forms: Solitary $(74 \%)$, which is the most frequent form seen usually in the face, and multiple (26\%) which is of dominant autonomic inheritance, the gene of the familiar cylindromatosis being located in the chromosome $16 q 12-q 13^{[13]}$ Histology is characterized by the presence of multiple compact epithelial lobes. Two types of cells are described: the central cells with clear nuclei; and the peripheral ones with small and dark nuclei. ${ }^{[14]}$ Differential diagnoses are necessary with other pathologies such as trichoepitheliomas, epitheliomas to basal cell nodules as also metastatic tumours, and trichofolliculomas.

Carcinoma of the sebaceous cells is a very rare tumour. It occurs in women between 60 and 70 years of age and is preferentially located on the eyelids. This carcinoma may appear as a solitary, yellowish, and painless nodule. Histology shows very cellular bands or basophilic masses extended from the dermis to the subcutaneous weave. $^{[15]}$

Metastasis takes place first in the regional lymphatic nodes and then, in the viscera, these carcinomas can also invade the facial bones.

A syringomoid eccrine carcinoma is also know as a microcystic adnexal carcinoma, malignant syringoma, or a sclerosing carcinoma of the eccrine sweat glands. It is pronounced in aged patients and is usually located on the scalp, face, trunk, and extremities. It is a solitary tumour presenting as a slow-growing nodule or plaque. It can appear with alopecia and the lesion may secrete fluid. The following characteristics are observed in the histological analysis: cellular atypia, nuclear hyperchromatism, deep invasion, and many tubulocystic proliferations at the level of the dermis..$^{[15]}$

In all our cases of adnexal skin carcinomas of the head and neck region, surgical excision was the treatment of choice, the excision and reconstruction being conducted simultaneously by the same team.

In previous reports, adnexal carcinomas have been considered to be radioresistant although new techniques of radiotherapy have been revaluated as part of primary and adjuvant treatments. ${ }^{[17,18]}$

Radical neck dissection must be done when metastatic cervical nodes are detected.

\section{CONCLUSION}

- Adnexal skin carcinomas are both very rare and infrequent compared to other nonmelanoma tumors (basal cells and squamous carcinomas).

- The head and the neck region is the favourite site of presentation.

- The treatment of election is a complete surgical resection of the tumor.

- When regional lymphatic metastatic nodes are present, radical neck dissection is the treatment of election.

- Revaluation of adjuvant radiation therapy is presently being considered.

- When the treatment is oncologically sufficient, the result is a safe and long survival.

\section{REFERENCES}

1. McKee Ph, Mariden R, Santacruz D. Tumors of the epithelial appendages. In: McKee Ph, Mariden R, Santacruz D, editors. London: Mosby Wolfe; 1996. p. 151-7.

2. Weedon D. Tumors of cutaneous appendage. In: Weedon D, editor. Skin pathology. London: Churchill Livingston; 1997. p. 713-58.

3. Moulin G, Balme B, Thomas L. Tumeurs bènignes de l'épiderme. Encycl. Med. Chir. Paris: Elsevier, Dermatologie; 1996.

4. Santacruz D. Tumors of sweat gland differentiation. In: Farmer E, Hood A, editors. Pathology of the skin. London: Appleton Lange; 1990. p. 624-66.

5. Grabb W, Smith J. Cirugía Plástica. Tercera edición. 1992. p. 534. Inwin L, Bainbridge L, Reid C. Department of plastic and reconstructive surgery, Royal Victoria Infirmary, Newcastle. Dermal Ecrine Cylindroma (Turban Tumour). Br J Plast Surg 1990;43:702-5.

6. Wyld L, Bullen S, Browning F. Department of surgical and anaesthetic sciences. The Royal Hallamshire Hospital, Sheffield, England. Transcranial erosion of a benign dermal cylindroma. Ann Plast Surg 1996;36:194-6.

Indian J Plast Surg July-December 2008 Vol 41 Issue 2 
7. Dissanayake R, Salm R. Sweat gland carcinomas: Prognosis related to histological type. Histopathology 1980;4:445.

8. Gertler W. Spieglersche. Tumoren mit ubergong im metatasienrendes Spinaliom. Dermatol Wochenschr 1953;128:673.

9. Greither A, Rehrmann A. Spiegler Karzinome mit assoziierten. Symtomen: Eim neves Syndrom? Dermatologica 1980;160:361.

10. Korting G, Hoede N, Gebbhardt R. Kurzer Bericht uber enien maligne entarteten Spiegler Tumor. Dermatologica 1970;156:141.

11. Lyon JB, Rovillard LM. Malignant degeneration of turban tumour of scalp. St Johns Hosp Dermatol Soc 1961;46:74.

12. Zontschew P. Cylindroma capitis mit maligner. Entartung Zentralbl Chir 1961;86:1875.

13. Stoll C, Alembik Y, Wilk A. Service de Genetique Medicale, Strabourg Hospital de Hautepierre: Familiar cylindromatosis. Genet Couns 2004;15:175-82.

14. Rossai J. Ackerman`s Surgical Pathology. Volumen 1. Octava edición, 2001.
15. Stawrianos S, Wilson GR, Lean LR. Department of plastic surgery, Newcastle General Hospital, Newcastle upon Tyne, UK. Adnexal Adenocarcinoma of the upper lip. Int J Oral Maxillofac Surg 1996;25:196-8.

16. Carpo BG, Grevelink JM, Grevelink SV. Laser treatment of pigmented lesions in children. Semin Cutan Med Surg 1999;18:233-43.

17. Yugueros P, Kane WJ, Goellner JR. Sweat gland carcinoma a clinicopathologic analysis of an expanded series in a single institution. Plast Reconsr Surg 1998;102:705-10.

18. Yen MT, Tse DT, Wu X, Wolfson AH. Radiation therapy for local central eyelid sebaceous cell carcinoma: Report two cases and review of the literature. Ophthal Plast Reconstr Surg 2000;16:211-5.

Source of Support: Nil, Conflict of Interest: None declared. 